\title{
Clozapine but not Haloperidol Re-establishes Normal Task-Activated rCBF Patterns in Schizophrenia within the Anterior Cingulate Cortex
}

\author{
Adrienne C Lahti',', Henry H Holcomb', Martin A Weiler', Deborah R Medoff', Kristin N Frey', \\ Michael Hardin' and Carol A Tamminga ${ }^{2}$ \\ 'Maryland Psychiatric Research Center, University of Maryland School of Medicine, Baltimore, MD, USA; ${ }^{2}$ University of Texas Southwestern \\ Medical School, Dallas, Texas
}

\begin{abstract}
Our previous work has identified that unmedicated volunteers with schizophrenia have regional cerebral blood flow (rCBF) activation patterns inappropriately related to the cognitive demand of a task in anterior cingulate cortex (ACC). Using positron emission tomography (PET) with ${ }^{15} \mathrm{O}$ water, we compared task-induced $\mathrm{rCBF}$ patterns induced by haloperidol or clozapine in individuals with schizophrenia. We hypothesized that clozapine, given its superior clinical action, would tend to normalize the abnormal task-activated response in ACC more than haloperidol. Schizophrenia volunteers (SVs) $(n=6)$ and normal volunteers (NVs) $(n=12)$ were trained to perform a tone discrimination task with 70-80\% accuracy. They were then scanned during three task conditions: (I) Rest, (2) sensory motor control (SMC) task, and (3) decision task (DEC). SVs were initially scanned after withdrawal of all psychotropic medication and again after treatment with therapeutic doses of haloperidol $(n=5)$ and/or clozapine $(n=5)$. rCBF values, sampled in the grown maxima of the task-activated ACC cluster, were analyzed between groups and task conditions. Task performance was similar across the unmedicated, haloperidol- and clozapine-medicated SV groups. There was a reduction in accuracy in the haloperidol SV group compared to the NVs. Group and task conditions affected rCBF in the ACC. Clozapine, but not haloperidol, reversed the abnormal ACC rCBF pattern in unmedicated SV to normal. The clozapine-treated SV group showed a rCBF pattern similar to the NV group in that ACC activation was not observed during the control task but occurred during the decision condition. The pattern seen in the haloperidoltreated SV group was similar to the unmedicated SV group in that ACC activation was seen during the control task and no further activation was seen during the DEC. We report that clozapine, but not haloperidol, normalizes anterior cingulate rCBF patterns in schizophrenia during a cognitive task. Based on these preliminary data, we propose that this pattern may account for the superior therapeutic effect of clozapine and represents a surrogate marker of this action.

Neuropsychopharmacology (2004) 29, I7I-I78 advance online publication, 8 October 2003; doi: I0.1038/sj.npp. I 3003 I 2
\end{abstract}

Keywords: schizophrenia; PET imaging; clozapine; haloperidol; anterior cingulate cortex

\section{INTRODUCTION}

Clozapine demonstrates a superior antipsychotic action in schizophrenia compared to other first- or second-generation antipsychotics (Kane et al, 1988; Conley et al, 1998; Breier et al, 1999; Wirshing et al, 1999; Kane et al, 2001). Moreover, in addition, it is not associated with Parkinsonism, akathisia, or tardive dyskinesia, and may improve cognitive function in schizophrenia (Buchanan and McKenna, 2000). When detected, clozapine-induced cognitive gains are modest and limited to discrete measures,

\footnotetext{
*Correspondence: Dr AC Lahti, Maryland Psychiatric Research Center, University of Maryland School of Medicine, PO Box 21247 , Baltimore, MD 21228, USA, Tel: + I-4l0-402-6842; Fax + I-410-402-6858, E-mail: alahti@mprc.umaryland.edu

Received 04 February 2003; revised II July 2003; accepted 20 August 2003

Online publication: 25 August 2003 at http://www.acnp.org/citations/ NPP0825030305 I/default.pdf
}

including verbal fluency, verbal memory, and attention (Goldberg et al, 1993; Hagger et al, 1993; Buchanan et al, 1994; Grace et al, 1996; Hoff et al, 1996; Galletly et al, 1997). Some aspects of clozapine's action on cognitive function, which form the basis for its long-term psychosocial benefits, may yet have to be quantified. These long-term psychosocial improvements occur in domains as diverse as quality of life (Galletly et al, 1997; Meltzer et al, 1990), compliance and treatment participation (Rosenheck et al, 1997; Luchins et al, 1998), violent behavior (Buchanan et al, 1998; Glazer and Dickson, 1998; Frankle et al, 2001), and substance abuse (Buckley et al, 1994). The mechanism of clozapine's unique antipsychotic efficacy is not known, but along with its benign motor effect profile, the clinical actions balance the significant agranulocytosis risk of the drug (Alvir et al, 1993).

Functional brain imaging techniques have advanced our understanding of the normal brain function and are now shaping our concepts of dysfunction in brain diseases. 
Functional imaging methodologies are used to understand how effective medications alter brain function to produce their therapeutic actions. Here, we present data contrasting a first-generation with a second-generation antipsychotic effects on task-activated regional cerebral blood flow (rCBF) in schizophrenia to determine the extent to which these medications can improve or 'normalize' the rCBF response in persons with the illness. Previous imaging studies have examined the effects of antipsychotics upon measures of attention. These reported increased metabolic rates in the striatum with haloperidol (Buchsbaum et al, 1992) and in the limbic cortex with clozapine and fluphenazine (Cohen et al, 1997). In this study, we postulated that clozapine, given its superior clinical action, would tend to normalize the abnormal task-activated $\mathrm{rCBF}$ response in persons with schizophrenia in anterior cingulate cortex (ACC) more than haloperidol (Holcomb et al, 2000).

\section{MATERIALS AND METHODS}

\section{Volunteers}

Six medically healthy persons with schizophrenia, treated with a variety of first- and second-generation antipsychotic medications, and 12 healthy normal volunteers (NVs) were recruited to participate in this study.

Persons with schizophrenia were recruited from the Residential Research Unit of the Maryland Psychiatric Research Center in Baltimore, MD, USA. Each underwent a structured clinical interview (SCID) for DSM-III-R at hospital admission. Two research psychiatrists reached a consensus diagnosis of schizophrenia based on the clinical interview plus all other sources of data utilizing DSM-III-R criteria.

The schizophrenia volunteer (SV) group, all right handed, included five male and one female persons with a mean age of $31.5 \pm 6.9$ years and a mean illness duration of $10.7 \pm 8.1$ years (see Table 1). All six were partially treatmentresponsive patients, who later, were discharged to community-based programs.

\section{Experimental Design}

At the start of the study, the SVs treatment was switched to a fixed dose $(0.3 \mathrm{mg} / \mathrm{kg})$ of haloperidol and no other neurally active medications for at least 4 weeks before medication withdrawal. After the four initial haloperidol week, all volunteers were withdrawn from haloperidol for $19.2 \pm 4.8$ days (range $=10-23$ days). All other aspects of inpatient treatment, such as groups or activity therapy, were continued. Single dose of lorazepam (1-2 mg) was occasionally given, but not within $48 \mathrm{~h}$ of scanning. The initial off-medication scan was completed in all six patient participants (see Table 1); then, five of the six patients were scanned again after receiving optimal therapeutic doses of haloperidol (average dose: $12 \pm 4.5 \mathrm{mg} /$ day) for $12 \pm 10$ weeks. Later, five of the six patient's medication was switched to clozapine; the switch was carried out by gradually increasing clozapine's dosage while tapering their antipsychotic treatment. They were scanned after receiving optimal therapeutic doses of clozapine (average dose: $280 \pm 135 \mathrm{mg} /$ day) for $23 \pm 12$ weeks. This was an open study where patients were not blind to medication status. In the haloperidol condition, the BPRS Total and the BPRS Psychosis mean scores off-drug were $33.0 \pm 8.4$ and $7.6 \pm 2.5$, respectively; on haloperidol, these scores were $38.2 \pm 14.0$ and $7.2 \pm 2.6$, respectively. In the clozapine condition, the BPRS Total and Psychosis mean scores offdrug were $37.5 \pm 6.0$ and $9.3 \pm 2.5$, respectively; on clozapine, they were $36.0 \pm 7.3$ and $7.8 \pm 1.7$, respectively. No comparisons of symptom scale scores between the medicated or unmedicated status showed differences.

The 12 NVs were recruited from the community through newspaper advertising and screened by telephone for lack of major medical or psychiatric illness. If suitable, they were further screened in face-to-face interviews using the SCIDnonpatient (SCID-NP) and structured interview for DSM III-R personality disorders (SIDP-R) to rule out current or past history of Axis I or Axis II disorders. A family history of schizophrenia in any first-degree relative of the prospective healthy volunteer was ruled out. Six controls were male and six were female, all were right handed, and their mean age was $28.4 \pm 4.6$ years.

Table I Characteristics of Study Population

\begin{tabular}{|c|c|c|c|c|c|c|c|c|c|c|c|c|c|}
\hline SV & Sex & Race & $\begin{array}{c}\text { Age } \\
\text { (years) }\end{array}$ & $\begin{array}{l}\text { Length of } \\
\text { illness } \\
\text { (years) }\end{array}$ & $\begin{array}{l}\text { Schizophrenia } \\
\text { subtype }\end{array}$ & $\mathbf{P A S}^{\mathbf{a}}$ & $\mathbf{P R O}^{\mathbf{b}}$ & $\begin{array}{c}\text { DFc } \\
\text { (days) }\end{array}$ & DF $\operatorname{scan}^{d}$ & $\begin{array}{l}\text { Haloperidol } \\
\text { scan }\end{array}$ & $\begin{array}{c}\text { Haloperidol } \\
\text { dose } \\
\text { (mg/day) }\end{array}$ & $\begin{array}{l}\text { Clozapine } \\
\text { scan }\end{array}$ & $\begin{array}{c}\text { Clozapine } \\
\text { dose } \\
\text { (mg/day) }\end{array}$ \\
\hline I & $M$ & $\mathrm{C}$ & 35 & 16 & Undiff. & 0.31 & 3 & 21 & Yes & Yes & 5 & Yes & 200 \\
\hline 2 & $M$ & C & 32 & 15 & Undiff. & 0.24 & 3 & 18 & Yes & & & Yes & 350 \\
\hline 3 & $M$ & C & 23 & 3 & Paranoid & 0.45 & 2 & 10 & Yes & Yes & 15 & Yes & 300 \\
\hline 4 & $M$ & C & 23 & 2 & Undiff. & 0.35 & 8 & 23 & Yes & Yes & 15 & & \\
\hline 5 & $\mathrm{~F}$ & C & 38 & 6 & Paranoid & 0.15 & 5 & 21 & Yes & Yes & 15 & Yes & 100 \\
\hline 6 & $M$ & $A$ & 38 & 22 & Paranoid & 0.25 & 6 & 22 & Yes & Yes & 10 & Yes & 450 \\
\hline
\end{tabular}

SV, schizophrenic volunteers; C, Caucasian individuals; A, Asian individuals; Undiff., Undifferentiated.

a Premorbid Adjustment Scale: Age scales total score (lower score is better).

bPrognostic Scale: General items total score (higher score is better).

'Drug-free (DF) period.

dDrug-free (DF) scan. 


\section{Informed Consent}

The University of Maryland School of Medicine's Institutional Review Board approved this protocol. Normal and schizophrenic volunteers were fully informed about the nature of the protocol and afterwards each of them gave informed consent. Only patients who were competent and judged clinically to be capable of understanding and appreciating the risks involved in this study were selected to participate. Separate clinicians including both the principal investigator and noninvestigator clinicians presented the nature of the protocol on several occasions and assessed their willingness to be involved. Prior to giving consent, schizophrenic volunteers completed an 'evaluation to sign consent' form, a questionnaire probing their understanding of various aspects of the study. Family members or caregivers were involved in the information process when available. Volunteers were reconsented prior to each new scanning session.

\section{Task Description and Training During rCBF}

The task condition (DEC) was a graded error rate, forcedchoice auditory discrimination task, described previously (Holcomb et al, 2000). Subjects were instructed to press a button held in their right hand immediately when they recognized a high-frequency reference tone $(1500 \mathrm{~Hz})$ and the button in their left hand with a lower-frequency tone $(800-1492 \mathrm{~Hz})$. An equal number of high and low tones lasting $100 \mathrm{~ms}$ each was randomly presented in each stimulus condition; 100 trials comprised each training set and 60 trials, each imaging set. An intertrial interval of $2 \mathrm{~s}$ (onset of first tone to onset of the subsequent tone) was fixed. Failure to respond was scored as an error. Response time was calculated from the onset of the stimulus to the button press.

During the active control task (sensory motor control, SMC), subjects heard the same sets of tones presented during the DEC task condition and merely alternated rightand left-hand button presses in synchrony with tone presentation. During the Rest condition, subjects were instructed to lie quietly: eyes were open and earphones were in place.

All subjects began training on the auditory discrimination task 2-5 weeks prior to the scan sessions. The purposes of the training were to eliminate stimulus or task novelty, determine what frequency difference would reliably provide $80 \%$ performance accuracy for each subject, and to reduce performance variability within and between volunteer groups. Volunteers were trained until they consistently achieved the required performance accuracy. Volunteers with schizophrenia were retrained prior to scan performed on haloperidol and clozapine.

\section{Positron Emission Tomography (PET) Imaging}

PET scans were obtained using the general electric $4096+$ system, which produces 15 brain image slices at an intrinsic resolution of $6.1 \mathrm{~mm}$ in each dimension. The bolus $\mathrm{H}_{2}^{15} \mathrm{O}$ method (Raichle et al, 1983) was used without arterial blood sampling. Approximately, $62 \mathrm{mCi} \mathrm{H}_{2}^{15} \mathrm{O}$ were administered on each occasion. Between scans 10-12 min elapsed. The
rCBF distribution was measured in each of the three condition: (1) Rest, (2) SMC, and (3) DEC utilizing four scans per condition (12 scans per subject). The order of the scans was fixed for all subjects: Rest, SMC, and DEC, consecutively repeated four times. Within a given scan, the frequencies of the two tones were held constant. The frequencies were chosen based on the training accuracy for that individual. In all, 60 trials were delivered during each scan; tones began $15 \mathrm{~s}$ prior to tracer delivery, and scan acquisition began $20 \mathrm{~s}$ after dose delivery. PET data were acquired for $60 \mathrm{~s}$.

\section{Image Analysis}

The qualitative PET blood flow images were analyzed with modified statistical parametric mapping (SPM) routines (Friston et al, 1996). The scans from each subject were realigned using the first as a reference. The alignment procedure was modified to use 10 iterations to optimize the spatial correlation between data sets; the default procedure uses three iterations. Following realignment, all images were transformed into a standard anatomical space (Talairach and Tournoux, 1988). Prior to generating the $\mathrm{SPM}_{(Z)}$ map, the data were smoothed using a $12-\mathrm{mm}$ Gaussian kernel. Only clusters of connected voxels (face or edge) above a threshold $(Z=2.33 P=0.01$, one-tailed, uncorrected for multiple comparisons) were tested for significance by means of spatial extent statistics, which set at an alpha level of $<0.05$ after correcting for multiple comparisons (Friston et al, 1996). The full-width at half-maximum of the average noise subtraction image was used to determine the number of resels (Worsley et al, 1992) available for analysis.

\section{STATISTICAL ANALYSIS}

\section{Behavioral Measures}

Behavioral outcome measures were extracted from all trials generated in DEC PET scans sessions. Outcome measures for two scanning sessions (one on haloperidol, one on clozapine) were unavailable because of computer recording problems. These measures include mean accuracy, mean response time, and mean frequency differences between high and low tones for accurate trials. Differences on those measures among each of the three SV groups (unmedicated, haloperidol, and clozapine medicated) and the NV group were tested using a Wilcoxon rank-sum test on all pairs. Differences among the three SV groups were tested using Kruskal-Wallis test. For behavioral measures generated in SMC PET scans sessions, differences among the three SV groups were tested using Kruskal-Wallis test.

\section{IMAGING}

\section{Region of Interest Analysis}

We evaluated the a priori hypothesis that clozapine would 'improve' the abnormal ACC rCBF pattern in schizophrenia to a greater degree than haloperidol. The maxima of the anterior cingulate/medial frontal cortex cluster activated with the normal performance of this task was identified (Talairach coordinates-02, 12, and 48) (Holcomb et al, 
2000). rCBF values were sampled in that maxima, grown to a $3 \times 3 \times 3$ pixel ROI, in each group during Rest, SMC, and DEC. A two-way ANOVA was performed to test for effects of task (Rest, SMC, and DEC) and group, for each of the SZ groups compared to the $\mathrm{NV}$ group. When an interaction was observed, a one-way ANOVA testing each of the tasks separately was obtained. Repeated measure ANOVA was performed to test the unmedicated SZ $v s$ the haloperidol SV and the unmedicated SZ vs the clozapine SZ groups.

\section{RESULTS}

\section{Task Performance With and Without Medication}

Performance characteristics of the SV on the auditory discrimination task during $\mathrm{rCBF}$ imaging were similar in the unmedicated, haloperidol-, and clozapine-medicated SV groups with respect to accuracy of task performance, response time, and frequency differences to achieve that accuracy (Table 2). There was no difference in response time between any of the SV groups compared to the NVs. However, there was a reduction in accuracy in the haloperidol SV group compared to the NVs (KruskalWallis, $\left.\chi^{2}=4.02, \mathrm{df}=1, P<0.045\right)$. Moreover, a greater frequency difference to achieve target accuracy was required in all of the SV groups compared to the NVs (for clozapine, $\chi^{2}=5.89, \mathrm{df}=1, \quad P<0.015$; for haloperidol, $\chi^{2}=7.13, \quad \mathrm{df}=1, \quad P<0.008$; and without medication, $\left.\chi^{2}=10.1, \mathrm{df}=1, P<0.002\right)$. Thus, all the SVs required a greater frequency difference between tones to perform the task at approximately $80 \%$ accuracy, which provided task performance at nearly the accuracy and response time level as the NVs. There were no significant differences in omission rate during the task between the unmedicated and haloperidol-medicated SV groups and between the unmedicated and clozapine-medicated SV groups. There were no significant differences in the performance characteristics during the control task between the unmedicated, haloperidol- and clozapine-medicated SV groups.

\section{Region of Interest Analysis: rCBF in ACC}

A significant interaction between tasks and groups was found between the NV and the unmedicated SZ groups ( $\mathrm{F}[2$,
$15]=7.72 ; P=0.005)$ and a trend between the NV and haloperidol SZ groups $(\mathrm{F}[2,14]=2.28 ; P=0.089)$. There was no interaction between the $\mathrm{NV}$ and clozapine $\mathrm{SZ}$ groups. rCBF differences in ACC were identified between the $\mathrm{NV}$ and unmedicated $\mathrm{SZ}$ groups during the control $(\mathrm{F}[1,16]=11.5 ; \quad P=0.004)$ and during the decision $(\mathrm{F}[1,15]=12.36 ; P=0.003)$ tasks, but not during Rest. Between the NV and haloperidol SZ groups, rCBF differences were identified during the control task $(\mathrm{F}[1,15]=6.19 ; P=0.025)$, but not during Rest or the decision task (DEC). (Figure 1). An inspection of the data suggests that the pattern of rCBF change across tasks was similar to the NV group when SV were treated with clozapine, but more similar to the unmedicated SV group when they were treated with haloperidol. Mean changes in $\mathrm{rCBF}$ values in ACC during the control and the DECs are presented in Table 3.

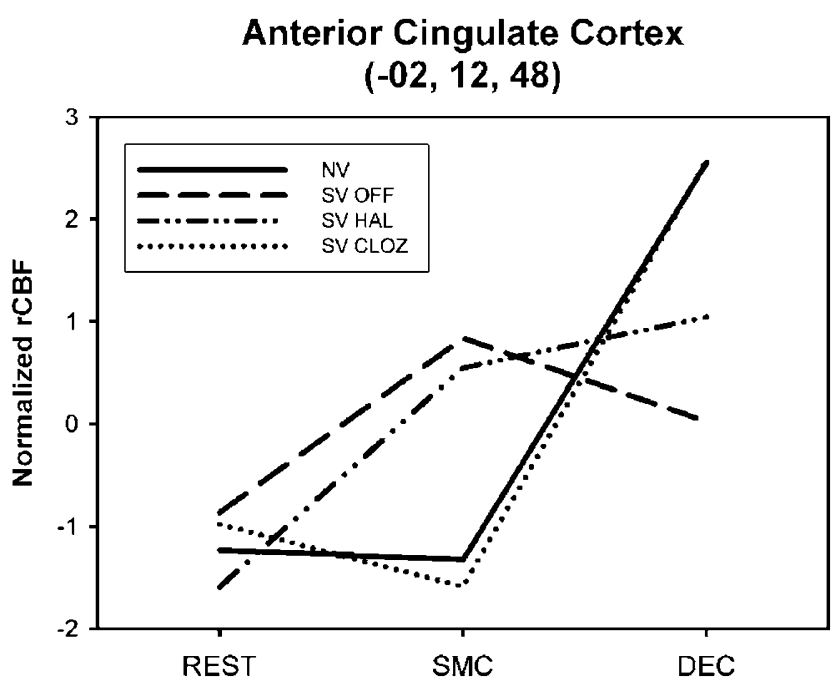

Figure I Normalized rCBF values sampled in the maxima of the anterior cingulate/medial frontal cortex cluster activated with the normal performance of the auditory DEC. Values were sampled at Rest, during the control task (SMC) and during the DEC. The clozapine group (SV OFF) $(n=5)$ showed a rCBF pattern similar to the NV group $(N V)(n=12)$ and the haloperidol group (SV HAL) $(n=5)$ showed a pattern similar to the unmedicated schizophrenia group (SV OFF) $(n=6)$.

Table 2 Auditory Recognition Task: Group Performance Characteristics

\begin{tabular}{|c|c|c|c|c|}
\hline & \% Accuracy mean, SD & $\%$ Omission mean, SD & Reaction time mean, SD & $\begin{array}{c}\text { Mean frequency } \\
\text { difference }(\mathrm{Hz}) \text { mean, SD }\end{array}$ \\
\hline Drug-free SV volunteers $(n=6)$ & $76.8( \pm 14.9)$ & $1.0( \pm 1.0)$ & $766.8( \pm 203.2)$ & $346.6 *( \pm 355.1)$ \\
\hline Haloperidol SV volunteers $(n=4)$ & $73.7^{*}( \pm 10.4)$ & $1.4( \pm 2.4)$ & $632.5( \pm 236.7)$ & $346.1 *( \pm 354.5)$ \\
\hline Clozapine SV volunteers $(n=4)$ & $76.3( \pm 8.0)$ & $1.0( \pm 1.8)$ & $678.2( \pm 152.8)$ & $314.4 *( \pm 340.6)$ \\
\hline Healthy volunteers $(n=12)$ & $80.6( \pm 4.7)$ & $0.7( \pm 0.9)$ & $735.0( \pm 102.0)$ & $17.2( \pm 8.3)$ \\
\hline
\end{tabular}

* Significantly different between this SV group and NVs.

There was no difference among the three SV groups on those measures. 
Table 3 Changes in Adjusted rCBF Values in ACC During Tasks

\begin{tabular}{lcc}
\hline & $\begin{array}{l}\text { Control task } \\
\text { (SMC-Rest) }\end{array}$ & $\begin{array}{l}\text { Decision task } \\
\text { (DEC-SMC) }\end{array}$ \\
\hline NV $(n=12)$ & $-0.1 \pm 1.9$ & $3.8 \pm 2.3$ \\
Unmedicated SV $(n=6)$ & $1.7 \pm 2.9$ & $-0.8 \pm 1.5$ \\
Haloperidol SV $(n=5)$ & $2.1 \pm 2.6$ & $0.5 \pm 3.3$ \\
Clozapine SV $(n=5)$ & $-0.6 \pm 1.6$ & $4.2 \pm 3.8$ \\
\hline
\end{tabular}

Descriptively, the NV group did not show ACC rCBF activation during the control task, but did show activation during the DEC. The clozapine SV group showed a similar pattern to the $\mathrm{NV}$ group. The unmedicated SV group showed ACC activation during the control and no further increase during the DEC. Similarly, the haloperidol SV group activated during the control task with no further increase during the DEC.

\section{DISCUSSION}

These results show that clozapine reverses the $\mathrm{rCBF}$ abnormalities in ACC found in schizophrenia whereas haloperidol does not. We, and others, have previously described the abnormal functioning of the ACC in schizophrenia using $\mathrm{rCBF}$, with the activation patterns inappropriately related to the cognitive demand of the task (Holcomb et al, 2000; Carter et al, 1997, 2001). This experiment confirms the previously identified pattern of ACC dysfunction in unmedicated SVs, and shows a clozapine-induced normalization of that dysfunction, strikingly different from the haloperidol-induced action. As task-activated $\mathrm{rCBF}$ is thought to represent changes in neuronal activity, these results suggest a physiologic basis for the superior action of clozapine in schizophrenia. There are two possible framework interpretations for our study: one is clozapine's superior therapeutic efficacy, the other is clozapine's effect on cognition.

In a landmark study, Kane et al (1988) demonstrated that clozapine was more effective than chlorpromazine for the treatment of positive symptoms in severe treatmentrefractory inpatients. Subsequent studies have confirmed these results (Rosenheck et al, 1997; Buchanan et al, 1998; Pickar et al, 1992; Breier et al, 1994; Essock et al, 1996; Conley et al, 1999). The advantage of clozapine over a firstgeneration antipsychotic medication was also found in partially responsive, community-based, schizophrenic patients (Kane et al, 2001; Buchanan et al, 1998; Breier et al, 1994). There is now convincing evidence that the ACC is involved in a distributed neural network that mediates psychosis (Cleghorn et al, 1992; Silbersweig et al, 1995; Szechtman et al, 1998; Shergill et al, 2000). rCBF in ACC significantly correlates with psychosis levels in unmedicated
SV (Tamminga et al, 2001; Lee et al, 2003). Psychosis exacerbation with the NMDA antagonist, ketamine, is accompanied by increases in ACC rCBF and the induced behavioral changes correlate with the ACC rCBF (Lahti et al, 1995; Holcomb et al, 2001). Thus, the suggestion that the normalization of $\mathrm{rCBF}$ in the schizophrenic ACC by clozapine mediates that drug's clinical advantage in psychosis is not without basis.

However, the rCBF changes with clozapine were seen during the performance of a task and clozapine treatment is associated with improved cognition. Several open-label and double-blind studies comparing clozapine to traditional antipsychotic with neurocognitive batteries have reported, almost unanimously, an improvement in verbal memory, visual attention, and verbal fluency with clozapine (Goldberg et al, 1993; Hagger et al, 1993; Buchanan et al, 1994; Grace et al, 1996; Hoff et al, 1996; Galletly et al, 1997). The gains, however, were modest and some negative effect, in visual memory for example, was noted as well (Goldberg and Weinberger, 1994).

Malfunctions of specific cognitive processes such as working memory (Goldman-Rakic, 1999), planning (Morris et al, 1995), context evaluation (Cohen et al, 1999), response selection and error monitoring (Carter et al, 2001), and learning and cognitive flexibility (Goldberg et al, 1990), have been implicated in the generation of the broad neuropsychologic deficits in schizophrenia (Saykin et al, 1991, 1994). The ACC is key to the performance of several of these basic mental operations, including attention, response selection, and error monitoring (Ghering et al, 1993; Carter et al, 1999, Peterson et al, 1999; Bush et al, 2000). Consistent with its demand on response selection, error monitoring and attention, the auditory task used in this study activates the caudal region of the ACC (Holcomb et al, 2000). One possible interpretation of our findings is that patients with schizophrenia already engage these processes during the control task (R/L button press) and that, with clozapine, they allocate these resources only during the DEC. Improved function in ACC could affect various aspects of cognition. For example, a normally functioning ACC could provide conflict-signal information and engage other part of the brain in adaptive cognitive processes (Carter et al, 1999). Subtle changes in cognition and daily functioning could be expected. This study suggests that even more comprehensive neurocognitive battery should be evaluated in connection with clozapine treatment.

Thus, there is adequate background support to interpret this study both as an effect on therapeutic efficacy and on cognition. In this study, our patient's clinical status did not significantly worsen during medication withdrawal. This and the small number of patients in this study do not provide enough power to perform correlations between ACC rCBF and behavioral changes. Thus, one can only speculate whether these changes are linked more to clozapine's therapeutic superiority on psychosis or its effects on cognition.

Several neurochemical mechanisms could be involved in the improved anterior cingulate function with clozapine. Clozapine has a relatively lower D2 receptor occupancy and a much broader receptor affinity profile than haloperidol, including high affinity for some of the serotonin, 
adrenergic, and cholinergic receptors (Arnt and Skarsfeldt, 1998). Several laboratories have shown that clozapine releases dopamine in frontal cortex in animal preparations, an action possibly related to its serotonin and/or noradrenergic receptor affinity (Pehek et al, 1994; Pehek, 1996; Rollema et al, 1997; Moghaddam and Bunney, 1999; Hertel et al, 1999; Youngren et al, 1999). In electrophysiologic and immediate-early gene studies, clozapine and other secondgeneration antipsychotics demonstrate limbic selectivity in that they preferentially affect dopamine neurons projecting to limbic areas (Chiodo and Bunney, 1983; White and Wang, 1983; Robertson and Fibiger, 1992). Also, unlike traditional antipsychotics, clozapine selectively antagonizes PCP or MK-801 actions on the CNS in animal behavioral models (Bakshi et al, 1994; Corbett, 1995; Arvanov and Wang, 1999). Whether clozapine's effect on rCBF patterns is linked to one or several of these properties needs to be established.

The flow differences reported here occur in the face of matched behavioral performance across the unmedicated and medicated SV groups. The lower performance associated with the haloperidol compared to the NV group does not appear to be related to a disrupting learning effect of haloperidol or the result of insufficient practice as all patients were trained to perform at a required level prior to the scanning session. These data are based on scans completed off all medication and on each drug alone (four of six volunteers were scanned in all three conditions; two of six in unmedicated and one drug conditions). In spite of these advantages, there are several limitations to this study. The number of patients studied is small. The study utilizes a fixed crossover design that cannot address possible order effects. These data, thus, should be considered as preliminary and replication will have to be established with larger samples.

We have identified that clozapine, but not haloperidol, normalizes cingulate rCBF patterns during a cognitive task. We propose that this pattern is associated with and represents a surrogate marker of the superior action of clozapine. As clozapine is the only second-generation antipsychotic with demonstrated superior efficacy (Conley et al, 1998; Breier et al, 1999; Wirshing et al, 1999), the mechanism of its therapeutic profile is particularly important to understand. The rCBF patterns identified here could lend guidance for preclinical antipsychotic models, strengthening or weakening current hypothesis. More importantly, they can provide rCBF pattern targets for the evaluation of potential new molecules for the treatment of schizophrenia. The availability of tissue-response targets could hasten the early and quick identification of promising drug candidates.

\section{ACKNOWLEDGEMENTS}

The William K Warren Medical Research Institute and the National Institute of Mental Health grants ROIMH57971 (ACL) and P30-MH40279 (IRC) supported this work. We thank all the volunteers with schizophrenia who took part in this project; Dale Warfel, Tamara Michaelidis, and the nursing staff of the RRU of the Maryland Psychiatric Research Center for clinical care.

\section{REFERENCES}

Alvir JM, Lieberman JA, Safferman AZ, Schwimmer JL, Schaaf JA (1993). Clozapine-induced agranulocytosis. Incidence and risk factors in the United States. $N$ Engl J Med 329: 162-167.

Arnt J, Skarsfeldt T (1998). Do novel antipsychotics have similar pharmacological characteristics? A review of the evidence. Neuropsychopharmacology 18: 63-101.

Arvanov VL, Wang RY (1999). Clozapine, but not haloperidol, prevents the functional hyperactivity of $N$-methyl-D-aspartate receptors in rat cortical neurons induced by subchronic administration of phencyclidine. J Pharmacol Exp Ther 289: 1000-1006.

Bakshi VP, Swerdlow NR, Geyer MA (1994). Clozapine antagonizes phencyclidine-induced deficits in sensorimotor gating of the startle response. J Pharmacol Exp Ther 271: 787-794.

Breier A, Buchanan RW, Kirkpatrick B, Davis OR, Irish D, Summerfelt A et al (1994). Effects of clozapine on positive and negative symptoms in outpatients with schizophrenia. Am J Psychiatry 151: 20-26.

Breier AF, Malhotra AK, Su TP, Pinals DA, Elman I, Adler CM et al (1999). Clozapine and risperidone in chronic schizophrenia: effects on symptoms, parkinsonian side effects, and neuroendocrine response. Am J Psychiatry 156: 294-298.

Buchanan R, McKenna P (2000). Clozapine clinical use and experience. In: Buckley PF, Waddington JL (eds). Schizophrenia and Mood Disorders: The New Drug Therapies in Clinical Practice. Butterworth-Heinemann: Oxford.. NPP_LPAGE-CITEXT; pp 21-31.

Buchanan RW, Breier A, Kirkpatrick B, Ball P, Carpenter Jr WT (1998). Positive and negative symptom response to clozapine in schizophrenic patients with and without the deficit syndrome. Am J Psychiatry 155: 751-760.

Buchanan RW, Holstein C, Breier A (1994). The comparative efficacy and long-term effect of clozapine treatment on neuropsychological test performance. Biol Psychiatry 136: 717-725.

Buchsbaum MS, Potkin SG, Siegel Jr BV, Lohr J, Katz M, Gottschalk LA et al (1992). Striatal metabolic rate and clinical response to neuroleptics in schizophrenia. Arch Gen Psychiatry 49: 966-974.

Buckley PF, Sajatovic M, Meltzer HY (1994). Treatment of delusional disorders with clozapine. Am J Psychiatry 1: 1394-1395.

Bush G, Luu P, Posner MI (2000). Cognitive and emotional influences in anterior cingulate cortex. Trends Cogn Sci 4: 215-222.

Carter CS, Botvinick MM, Cohen JD (1999). The role of the anterior cingulate cortex in executive processes of cognition. Rev Neurosci 10: 49-57.

Carter CS, MacDonald III AW, Ross LL, Stenger VA (2001). Anterior cingulate cortex activity and impaired self-monitoring of performance in patients with schizophrenia: an event-related fMRI study. Am J Psychiatry 158: 1423-1428.

Carter CS, Mintun M, Nichols T, Cohen JD (1997). Anterior cingulate gyrus dysfunction and selective attention deficits in schizophrenia: $\mathrm{H}_{2}^{15} \mathrm{O}$ PET study during single-trial Stroop Task Performance. Am J Psychiatry 154: 1670-1675.

Chiodo LA, Bunney BS (1983). Typical and atypical neuroleptics: differential effects of chronic administration on the activity of A9 and A10 midbrain dopaminergic neurons. J Neurosci 3: 1607-1619.

Cleghorn JM, Franco S, Szechtman B, Kaplan RD, Szechtman H, Brown GM et al (1992). Toward a brain map of auditory hallucinations. Am J Psychiatry 149: 1062-1069.

Cohen JD, Barch DM, Carter C, Servan-Schreiber D (1999). Context-processing deficits in schizophrenia: converging evi- 
dence from three theoretically motivated cognitive tasks. J Abnorm Psychol 108: 120-133.

Cohen RM, Nordahl TE, Semple WE, Andreason P, Litman RE, Pickar D (1997). The brain metabolic patterns of clozapine- and fluphenazine-treated patients with schizophrenia during a continuous performance task. Arch Gen Psychiatry 54: 481-486.

Conley RR, Tamminga CA, Bartko JJ, Richardson C, Peszke M, Lingie J et al (1998). Olanzapine compared with chlorpromazine in treatment-resistant schizophrenia. Am J Psychiatry 155: 914-920.

Conley RR, Tamminga CA, Kelly DL, Richardson CM (1999). Treatment-resistant schizophrenic patients respond to clozapine after olanzapine non-response. Biol Psychiatry 146: 73-77.

Corbett R (1995). Clozapine but not haloperidol antagonizes an MK-801 discriminative stimulus cue. Pharmacol Biochem Behav 51: 561-564.

Essock SM, Hargreaves WA, Covell NH, Goethe J (1996). Clozapine's effectiveness for patients in state hospitals: results from a randomized trial. Psychopharmacol Bull 32: 683-697.

Frankle W, Shera D, Berger-Hershkowitz H, Evins A, Connolly C, Goff D et al (2001). Clozapine-associated reduction in arrest rates of psychotic patients with criminal histories. $\mathrm{Am} \mathrm{J}$ Psychiatry 158: 270-274.

Friston KJ, Holmes A, Poline J, Price CJ, Frith CD (1996). Detecting activations in PET and fMRI: levels of inference and power. NeuroImage 4: 223-235.

Galletly CA, Clark CR, McFarlane AC, Weber DL (1997). Relationships between changes in symptom ratings, neurophysiological test performance and quality of life in schizophrenic patients treated with clozapine. Psychiatry Res 72: 161-166.

Ghering WJ, Goss B, Coles MGH, Meyer DE, Donchin E (1993). A neural system for error detection and compensation. Psychol Sci 4: 385-390.

Glazer WM, Dickson RA (1998). Clozapine reduces violence and persistent aggression in schizophrenia. $J$ Clin Psychiatry 59(Suppl. 3): 8-14.

Goldberg TE, Greenberg RD, Griffin SJ, Gold JM, Kleinman JE, Pickar D et al (1993). The effect of clozapine on cognition and psychiatric symptoms in patients with schizophrenia. $\mathrm{Br}$ J Psychiatry 162: 43-48.

Goldberg TE, Saint-Cyr JA, Weinberger DR (1990). Assessment of procedural learning and problem solving in schizophrenic patients by Tower of Hanoi type tasks. J Neuropsychiatry Clin Neurosci 2: 165-173.

Goldberg TE, Weinberger DR (1994). The effects of clozapine on neurocognition: an overview. J Clin Psychiatry 55(Suppl. B): $88-90$.

Goldman-Rakic PS (1999). The physiological approach: functional architecture of working memory and disordered cognition in schizophrenia. Biol Psychiatry 146: 650-661.

Grace J, Bellus SB, Raulin ML, Herz MI, Priest BL, Brenner V et al (1996). Long-term impact of clozapine and psychosocial treatment on psychiatric symptoms and cognitive functioning. Psychiatry Serv 47: 41-45.

Hagger C, Buckley P, Kenny JT, Friedman L, Ubogy D, Meltzer HY (1993). Improvement in cognitive functions and psychiatric symptoms in treatment-refractory schizophrenic patients receiving clozapine. Biol Psychiatry 34: 702-712.

Hertel P, Fagerquist MV, Svensson TH (1999). Enhanced cortical dopamine output and antipsychotic-like effects of raclopride by alpha2 adrenoceptor blockade. Science 286: 105-107.

Hoff AL, Faustman WO, Wieneke M, Espinoza S, Costa M, Wolkowitz O et al (1996). The effects of clozapine on symptom reduction, neurocognitive function, and clinical management in treatment-refractory state hospital schizophrenic inpatients. Neuropsychopharmacology 15: 361-369.

Holcomb HH, Lahti AC, Medoff DR, Weiler MW, Dannals RF, Tamminga CA (2000). Brain activation patterns in schizophrenic and comparison volunteers during matched-performance auditory recognition task. Am J Psychiatry 157: 1634-1645.

Holcomb HH, Lahti AC, Medoff DR, Weiler MW, Tamminga CA (2001). Sequential regional cerebral blood flow brain scans using PET with $\mathrm{H}_{2}^{15} \mathrm{O}$ demonstrate ketamine actions in CNS dynamically. Neuropsychopharmacology 25: 165-172.

Kane J, Honifeld G, Singer J, Meltzer H (1988). Clozapine for the treatment-resistant schizophrenic: a double-blind comparison with chlorpromazine. Arch Gen Psychiatry 45: 789-796.

Kane JM, Marder SR, Schooler NR, Wirshing WC, Umbricht D, Baker RW et al (2001). Clozapine and haloperidol in moderately refractory schizophrenia: a 6-month randomized and doubleblind comparison. Arch Gen Psychiatry 58: 965-972.

Lahti AC, Holcomb HH, Medoff DR, Tamminga CA (1995). Ketamine activates psychosis and alters limbic blood flow in schizophrenia. Neuroreport 6: 869-872.

Lee SM, Weiler MA, Holcomb HH, Tamminga CA, Lahti AC (2003). Correlations between rCBF and behavior in drug-free schizophrenic patients. Schizophrenia Res 60: 227.

Luchins DJ, Hanrahan P, Shinderman M, Lagios L, Fichtner CG (1998). Initiating clozapine treatment in the outpatient clinic: service utilization and cost trends. Psychiatry Serv 49: 1034-1038.

Meltzer HY, Burnett S, Bastani B, Ramirez LF (1990). Effects of six months of clozapine treatment on the quality of life of chronic schizophrenic patients. Hosp Community Psychiatry 41: 892-897.

Moghaddam B, Bunney BS (1999). Acute effects of typical and atypical antipsychotic drugs on the release of dopamine from prefrontal cortex, nucleus accumbens, and striatum of prefrontal cortex, and striatum of the rat: an in vivo microdialysis study. Neuropharmacology 20: 1755-1760.

Morris RG, Rushe T, Woodruffe PW, Murray R (1995). Problem solving in schizophrenia: a specific deficit in planning ability. Schizophr Res 14: 235-246.

Pehek EA (1996). Local infusion of the serotonin antagonist's ritanserin or ICS 205,931 increases in vivo dopamine release in the rat medial prefrontal cortex. Synapse 24: 18-24.

Pehek EA, Meltzer HY, Yamamoto BK (1994). The atypical antipsychotic drug amperozide enhances rat cortical and striatal dopamine efflux. Eur J Pharmacol 240: 107-109.

Peterson BS, Skudlarski P, Gatenby JC, Zhang H, Anderson AW, Gore JC (1999). An fMRI study of stroop word-color interference: evidence for cingulate subregions subserving multiple distributed attentional systems. Biol Psychiatry 45: 1237-1258.

Pickar D, Owen RR, Litman RE, Konicki E, Gutierrez R, Rapaport MH (1992). Clinical and biologic response to clozapine in patients with schizophrenia. Crossover comparison with fluphenazine. Arch Gen Psychiatry 49: 345-353.

Raichle ME, Martin WR, Hersevitch P, Mintun MA, Markham J (1983). Brain blood flow measured with intravenous $\mathrm{H}_{2}^{15} \mathrm{O}$. Implementation and validation. Nucl Med 24: 790-798.

Robertson GS, Fibiger HC (1992). Neuroleptics increase C-FOS expression in the forebrain: Contrasting effects of haloperidol and clozapine. Neuroscience 46: 315-328.

Rollema H, Lu Y, Schmidt AW, Zorn SH (1997). Clozapine increases dopamine release in prefrontal cortex by 5-HT1A receptor activation. Eur J Pharmacol 338: R3-R5.

Rosenheck R, Cramer J, Xu W, Thomas J, Henderson W, Frisman L et al (1997). Comparison of clozapine and haloperidol in hospitalized patients with refractory schizophrenia. Department of Veterans Affairs Cooperative Study Group on Clozapine in Refractory Schizophrenia. N Engl J Med 337: 809-815.

Saykin AJ, Gur RC, Gur RE, Mozley PD, Mozley LH, Resnick SM et al (1991). Neuropsychological function in schizophrenia. Selective impairment in memory and learning. Arch Gen Psychiatry 48: 618-624.

Saykin AJ, Shtasel DL, Gur RC, Kester DB, Mozley LH, Stafiniak P et al (1994). Neuropsychological deficits in neuroleptic naive 
patients with first-episode schizophrenia. Arch Gen Psychiatry 51: 124-131.

Shergill SS, Brammer MJ, Williams SC, Murray RM, McGuire PK (2000). Mapping auditory hallucinations in schizophrenia using functional magnetic resonance imaging. Arch Gen Psychiatry 57: 1033-1038.

Silbersweig DA, Stern E, Frith C, Cahill C, Holmes A, Grootoonk S et al (1995). A functional neuroanatomy of hallucinations in schizophrenia. Nature 378: 176-179.

Szechtman H, Woody E, Bowers KS, Nahmias C (1998). Where the imaginal appears real: a positron emission tomography study of auditory hallucinations. Proc Natl Acad Sci USA 95: 1956-1960.

Talairach J, Tournoux P (1988). A Co-planar Stereotaxic Atlas of the Human Brain. Georg Thieme Verlag: New York.

Tamminga CA, Lahti CA, Medoff DR, Holcomb HH (2001). The functional involvement of the anterior cingulate cortex in schizophrenic psychosis. In Helmchen H, Henn F, Sartorius $\mathrm{H}$ (eds). Psychiatrie Gengenwart. Springer Verlag: KG Berlin, Heidleberg, Germany.

White FJ, Wang RY (1983). Differential effects of classical and typical antipsychotic drugs on A9 and A10 dopamine neurons. Science 221: 1054-1057.

Wirshing DA, Marshall Jr BD, Green MF, Mintz J, Marder SR, Wirshing WC (1999). Risperidone in treatment-refractory schizophrenia. Am J Psychiatry 156: 1374-1379.

Worsley KJ, Evans AC, Marrett S, Neelin P (1992). A threedimensional statistical analysis for CBF activation studies in human brain. J Cereb Blood Flow Metab 12: 900-918.

Youngren KD, Inglis FM, Pivirotto PJ, Jedema HP, Bradberry CW, Goldman-Rakic PS et al (1999). Clozapine preferentially increases dopamine release in the rhesus monkey prefrontal cortex compared with the caudate nucleus. Neuropsychopharmacology 20: 403-412. 